\title{
Functional similarities of asbestosis and cryptogenic fibrosing alveolitis
}

\author{
JAMES MARKOS, ARTHUR WILLIAM MUSK, KEVIN E FINUCANE
}

From the Departments of Respiratory Medicine and Pulmonary Physiology, Sir Charles Gairdner Hospital, Perth, Western Australia

ABSTRACT The pathological features in the lung in asbestosis and cryptogenic fibrosing alveolitis are ${ }_{\circ}^{\infty}$ similar. Patients with asbestosis, however, appear to have less severe impairment of transfer factor ${ }_{-}^{\circ}$ (TLCO) than those with fibrosing alveolitis for a given level of radiographic abnormality whencs assessed on the basis of the International Labour Organisation (ILO) profusion score. The $\mathbb{D}^{\circ}$ impairment of lung function in the two disorders has been compared in more detail in 29 patients with $\frac{\mathbb{D}}{3}$ asbestosis and 25 with fibrosing alveolitis, arterial oxygen desaturation during exercise being used to define the severity of the disorders. Arterial oxygen saturation (ear oximeter) and oxygen uptake were measured during incremental exercise on a cycle ergometer. TLCO (single breath technique) and total $\left.\right|_{\infty} ^{\circ}$ lung capacity (TLC, plethysmograph) were measured. Chest radiographs were graded for profusion. ${ }^{\circ}$ according to the ILO international classification. Patients with asbestosis had significantly higherO mean values for TLCO and TLC and lower mean profusion scores than those with fibrosing alveolitis. When stratified for the degree of arterial oxygen desaturation, however, no significant differences. were found in TLCO, TLC, or profusion score between the two disorders. To the extent that arterial oxygen desaturation with exercise reflects the morphological severity of the disease, these results $\stackrel{\varrho}{\rightarrow}$ suggest that, for a given degree of interstitial lung disease, asbestosis and cryptogenic fibrosing alveolitis are functionally and radiologically similar.

\section{Introduction}

A common problem in suspected occupational lung disease is to establish a cause and effect relationship between a given inhaled agent and the functional or structural abnormality detected.' A typical example is seen in asbestosis, where the morphological features in the lung are indistinguishable from those of cryptogenic fibrosing alveolitis apart from the presence of asbestos bodies and asbestos fibres. ${ }^{2}$ Comparison of the abnormalities of lung function in the two conditions may permit identification of features unique to either disorder, and hence may assist in distinguishing the two disorders.

Previous work examining the relationship between the functional and radiographic abnormalities in asbestosis and cryptogenic fibrosing alveolitis ${ }^{3}$ has

Address for reprint requests: Dr A W Musk, Department of Respiratory Medicine, Sir Charles Gairdner Hospital, Nedlands 6009, Western Australia, Australia.

Accepted 5 May 1988 shown that, for a given degree of reduction of carbon monoxide transfer factor (TLCo), the radiographic profusion score ${ }^{4}$ was greater in patients with asbes- -0 tosis. One interpretation of this finding is that there is a different relation between structure and function in the $\delta$ two conditions. Alternative explanations include the possibilities that the radiograph does not reflecto morphological severity equally in asbestosis and cryp-? togenic fibrosing alveolitis, and disordered function correlates poorly with morphological changes.

The relation between disordered structure and lung. $\%$ function in patients with asbestosis and cryptogenic N fibrosing alveolitis has not been reported independently of other pneumoconioses. In cryptogenic ${ }_{\sigma}$ fibrosing alveolitis, the morphological severity of the disorder, in terms of the intensity of interstitial fibrosis and inflammation, correlates well with arterial oxygen desaturation with exercise ${ }^{5}$ and this may therefore provide a more valid basis than the chest radiograph for comparing disordered function of the lung in the

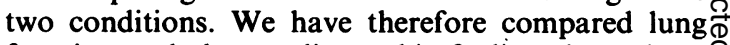
function and chest radiographic findings in patients $\frac{\varrho}{\sigma}$ 
with asbestosis and cryptogenic fibrosing alveolitis, using the degree of arterial oxygen desaturation with exercise to define the severity of the disease.

\section{Methods}

\section{PATIENTS}

We included in the study all patients with asbestosis and cryptogenic fibrosing alveolitis referred for assessment of lung function and response to exercise from January 1981 to January 1986 . There were 29 patients with asbestosis and 25 with cryptogenic fibrosing alveolitis. Asbestosis was defined on the basis of a history of occupational exposure to asbestos and the presence of diffuse small irregular opacities on the chest radiograph. Cryptogenic fibrosing alveolitis was defined according to the criteria of Turner-Warwick and Haslam. ${ }^{67}$ Patients with clinical evidence of connective tissue disorders (for example, rheumatoid arthritis, systemic sclerosis, polymyositis, systemic lupus erythematosus) were not included because their exercise capacity and degree of arterial oxygen desaturation may have been influenced by pulmonary vascular disease or extrapulmonary manifestations of the disease. Patients with radiographic emphysema, severe airflow obstruction ( $\mathrm{FEV}_{1} /$ forced vital capacity $<50 \%$ ), silicoasbestosis (predominant upper zone fibrosis), progressive massive fibrosis, previous lobectomy or pneumonectomy, persisting pleural effusion, pulmonary or pleural malignancy, or left ventricular failure were also excluded.

\section{LUNG FUNCTION}

Total lung capacity (TLC), vital capacity (VC), and residual volume (RV) were measured plethysmographically (Collins, model 09103). ${ }^{8} \mathrm{FEV}_{\text {, }}$ and forced vital capacity (FVC) were obtained with a digital spirometer (Hewlett-Packard, model 47303A). Transfer factor (TLCO) and transfer factor corrected for effective alveolar volume (KCO) were assessed by the single breath technique (Morgan, model TTB). ${ }^{9}$ All values were also expressed as percentages of the predicted value. ${ }^{1011}$

\section{EXERCISE TESTING}

A progressive exercise test was performed on a bicycle ergometer (Siemens-Elema, Model 62.03.178)..$^{12}$ Workload (W) was increased each minute by 100 kilopondmetres $(\mathrm{kpm}) / \mathrm{min}(1 \mathrm{kpm}=0.163$ watt). Continuous measurements were made of heart rate, ventilation $(\dot{V} E)$, oxygen uptake $\left.\left(\dot{V}^{\circ}\right)_{2}\right)$, carbon dioxide production, and arterial oxygen saturation $\left(\mathrm{SaO}_{2}\right)$, which was meacured with an ear oximeter (HewlettPackard, model 47201A). Measurements over the final 20 seconds of each workload were averaged by online computer to provide the data points for each workload. Data were collected only for completed one minute increments of work. Predicted values for maximum workload (Wmax) and maximum oxygen uptake $\left(\mathrm{Vo}_{2}\right.$ max $)$ were obtained from the age and sex adjusted equations of Jones et al. ${ }^{12}$ The maximum ventilation (VEmax) possible was estimated as FEV $\times 351 . \mathrm{min}^{-1}$. To compare arterial oxygen desaturation during exercise between subjects with different exercise capacities, change in $\mathrm{SaO}_{2}$ during exercise $\left(\Delta \mathrm{SaO}_{2}\right)$, was expressed relative to change in work output $\left(\Delta \mathrm{SaO}_{2}\right)$ $\left.\Delta \mathrm{W}, \% .100 \mathrm{kpm}^{-1} \cdot \mathrm{min}^{-1}\right)$ and to change in oxygen uptake $\left(\Delta \mathrm{SaO}_{2} / \Delta \mathrm{VO}_{2}, \% .1^{-1} \cdot \mathrm{min}^{-1}\right)$, both being calculated by linear regression analysis of all data points obtained during exercise. Measurement of lung function and the exercise study were usually performed within one week of each other; the longest interval was six months. Where serial measurements had been made to monitor disease progression in an individual, the most recent results were used.

\section{RADIOLOGY}

The standard plain chest radiograph that was closest in time to the exercise test was obtained; the longest interval was four years, and radiographs obtained the same day represented the median interval. The degree of abnormality of the chest radiograph was assessed according to the 1980 ILO International Classification of Radiographs of the Pneumoconioses ${ }^{4}$ for profusion of small opacities and degree of pleural disease. The radiographs were graded independently by three trained observers without knowledge of the clinical details or the results of lung function tests. Subjects were included only if at least two of the observers graded profusion as $\geqslant 1 / 0$. An ILO "score" was obtained for each subject by applying a 12 point scale to the ILO profusion grade assigned by each observer as follows: $0 /-=1,0 / 0=2,0 / 1=3,1 / 0=4,1 / 1=5$, $1 / 2=6,2 / 1=7,2 / 2=8,2 / 3=9,3 / 2=10,3 / 3=11$, $3 /+=12$. The ILO score for each subject was calculated as the mean score of all three observers.

\section{ANALYSIS}

Statistical comparisons were made by means of a two tailed Student's $t$ test with Bessel's correction and of linear regression analysis using the sum of the least squares method. P values of $<0.05$ (two tailed test) were accepted as indicating statistical significance.

Because the distribution of $\Delta \mathrm{SaO}_{2}$ was different in the two groups, statistical comparison was also made by stratifying the subjects into five groups on the basis of $\Delta \mathrm{SaO}_{2} / \Delta \mathrm{VO}_{2}$ values: group $1,>0$; group 2,0 to -1.9 ; group $3,-2.0$ to -4.9 ; group $4,-5.0$ to -9.9 ; group $5, \leqslant-10.0 \% .1^{-1} \cdot \mathrm{min}^{-1}$. 
Table 1 Clinical and physiological characteristics of the subjects

\begin{tabular}{|c|c|c|c|}
\hline & $\begin{array}{l}\text { Fibrosing } \\
\text { alveolitis } \\
(n=25)\end{array}$ & & $\begin{array}{l}\text { Asbestosis } \\
(n=29)\end{array}$ \\
\hline $\begin{array}{l}\text { Sex }(M: F) \\
\text { Age (y, mean (SD)) } \\
\text { Smoking (mean (SD) pack years) } \\
\text { Non-smokers (n) } \\
\text { Clubbing (n) } \\
\text { Crackles (n) }\end{array}$ & $\begin{array}{l}21: 4 \\
55(15) \\
42(37) \\
4 \\
15 \\
25\end{array}$ & & $\begin{array}{l}29: 0 \\
56(8) \\
30(21) \\
3 \\
6 \\
25\end{array}$ \\
\hline \multicolumn{4}{|l|}{ Lung function indices (mean (SD)) } \\
\hline 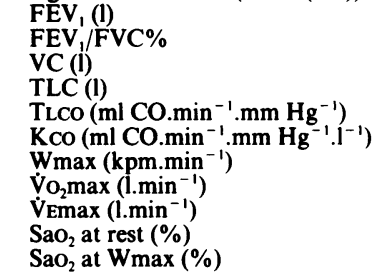 & $\begin{array}{l}2 \cdot 3(0 \cdot 8) \\
77(10) \\
3 \cdot 1(1 \cdot 2) \\
4 \cdot 6(1 \cdot 6) \\
11 \cdot 2(4 \cdot 8) \\
2 \cdot 9(1 \cdot 0) \\
568(219) \\
1 \cdot 3(0 \cdot 4) \\
66 \cdot 1(19 \cdot 2) \\
92 \cdot 5(4 \cdot 4) \\
94 \cdot 2(4 \cdot 2)\end{array}$ & $* * *$ & $\begin{array}{l}2 \cdot 4(0 \cdot 6) \\
77(8) \\
3 \cdot 2(0 \cdot 7) \\
5 \cdot 2(0 \cdot 9) \\
18 \cdot 5(4 \cdot 5) \\
4 \cdot 1(1 \cdot 1) \\
641(219) \\
1 \cdot 5(0 \cdot 4) \\
60 \cdot 5(16 \cdot 6) \\
95 \cdot 6(1.6) \\
83.5(12 \cdot 0)\end{array}$ \\
\hline
\end{tabular}

Significance of difference of means: ${ }^{* *} p<0.01 ;{ }^{* * *} p<0.001$.

$\mathrm{FEV}_{1}$ - forced expiratory volume in one second; FVC - forced vital capacity; VC - vital capacity; TLC - total lung capacity; TLCocarbon monoxide transfer factor; Kco-transfer coefficient; Wmax -maximum workload; $\mathrm{Vo}_{2} \max$-maximum oxygen uptake; VEmax-maximum ventilation; $\mathrm{SaO}_{2}$-arterial oxygen saturation.

\section{Results}

\section{PATIENTS}

All 29 subjects with asbestosis and 21 of the 25 subjects with cryptogenic fibrosing alveolitis were male. The
Table 2 Chest radiographic profusion score and pleural disease

\begin{tabular}{|c|c|c|}
\hline & $\begin{array}{l}\text { Fibrosing } \\
\text { alveolitis } \\
(n=25)\end{array}$ & $\begin{array}{l}\text { Asbestosis } \\
(n=29)\end{array}$ \\
\hline Pleural disease* $(n)$ & 9 & 18 \\
\hline $\begin{array}{c}\text { ILO profusion grade* } \\
1(1 / 0,1 / 1,1 / 2) \\
2(2 / 1,2 / 2,2 / 3) \\
3(3 / 2,3 / 3,3 /+)\end{array}$ & $\begin{array}{l}7(1) \dagger \\
9(6) \dagger \\
9(2) \dagger\end{array}$ & $\begin{array}{l}18(12) \dagger \\
10(5) \dagger \\
1(1) \dagger\end{array}$ \\
\hline Mean (SD) ILO score $\ddagger$ & $8 \cdot 3(2 \cdot 2)$ & $6 \cdot 1(1 \cdot 8)$ \\
\hline Mean ILO profusion $\ddagger$ & $2 / 2$ & $1 / 2$ \\
\hline
\end{tabular}

*Agreement by at least two of three observers.

$\dagger$ The number in parentheses is the number of subjects with pleural disease.

†ILO score calculated from 12 point scale applied to ILO profusion grade (see under "Methods"). The mean ILO profusion is theo profusion grade closest to the mean ILO score according to the $12 \mathrm{~J}$ point scale.

mean age and smoking history were similar in the two groups (table 1). The diagnosis was confirmed by biopsy in one subject with asbestosis and in 20 withe cryptogenic fibrosing alveolitis. The median duration $\infty$ of asbestos exposure for the 29 subjects with asbestosis was four years (range three months to 30 years); 17 had been exposed to crocidolite at Wittenoom Gorge in Western Australia during 1943-66. The chest radiographic profusion score was greater in patients $\mathbb{D}$ with cryptogenic fibrosing alveolitis whereas pleural $\stackrel{\varrho}{\rightarrow}$

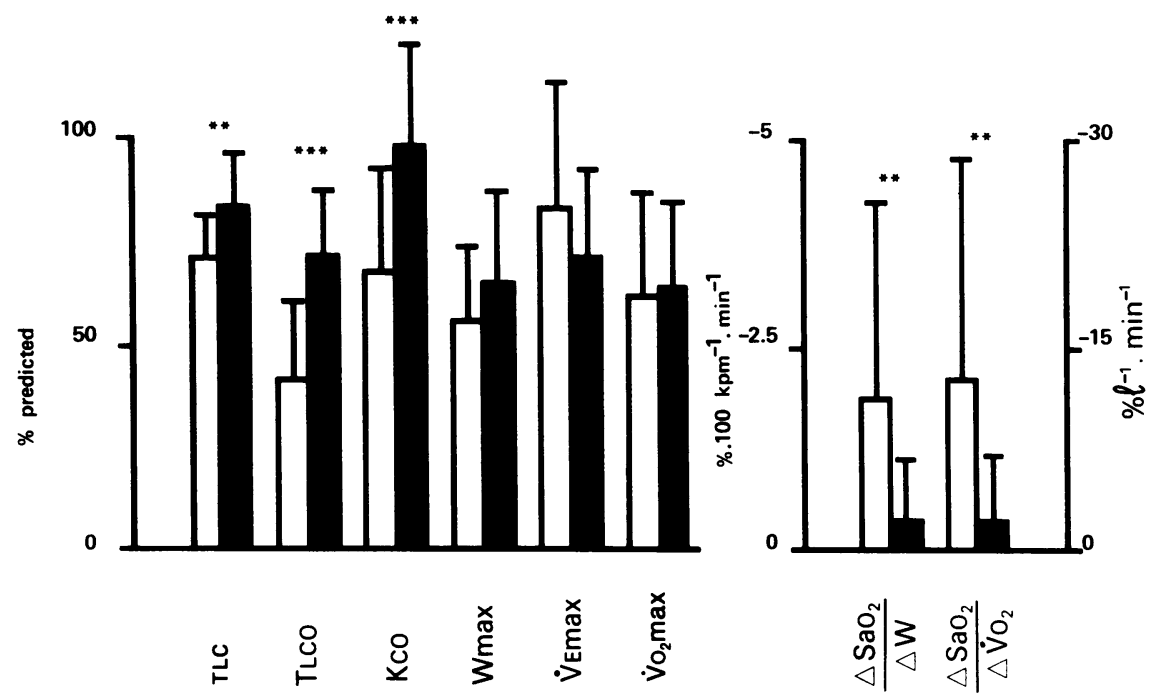

Fig 1 Resting and exercise lung function indices for patients with cryptogenic fibrosing alveolitis (open bars) and asbestosis (closed bars). Mean values (with 1 SD) are given as percentages of the predicted values, except for $\triangle \mathrm{SaO}_{2} / \triangle W$ and $\triangle \mathrm{SaO}_{2} / \Delta \dot{V} \mathrm{O}_{2}$, which are given in the units measured. TLC-total lung capacity; TLCO-carbon monoxide transfer factor; KCO-transfer coefficient;

Wmax-maximum workload; $\dot{V}$ Emax - maximum ventilation; $\dot{V} o_{2}$ max-maximum oxygen consumption; $\mathrm{SaO}_{2}$-arterial oxygen saturation. ${ }^{* *} p<0.01 ;{ }^{* * *} p<0.001$. 
Cryptogenic

fibrosing alveolitis

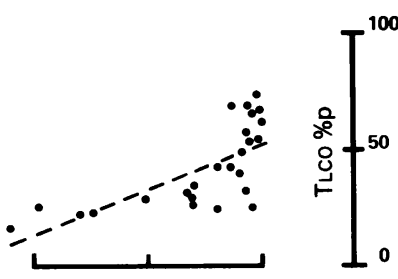

Asbestosis
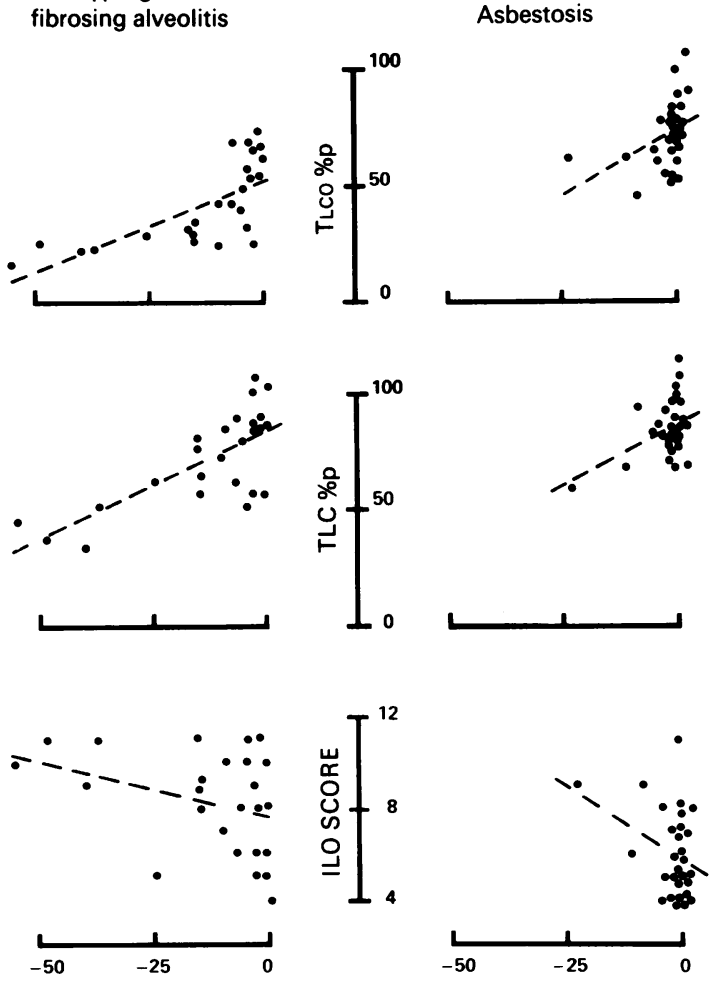

$\Delta \mathrm{SaO}_{2} / \Delta \dot{\mathrm{VO}}_{2}\left(\% \mathrm{I}^{-1} \cdot \mathrm{min}^{-1}\right)$

Fig 2 Relation between arterial oxygen desaturation with exercise and carbon monoxide transfer factor (TLCO), total lung capacity (TLC), and ILO score. Linear correlation coefficients: cryptogenic fibrosing alveolitis-TLCO, $r=0.69$ $(p<0.001)$; TLC, $r=0.72(p<0.001)$; ILO score, $r=-0.39(p>0.05) ;$ asbestosis-TLCO, $r=0.40$ $(p<0.05)$; TLC, $r=0.43(p<0.05)$; ILO score, $r=-0.34(p>0.05)$. Other abbreviations as in figure 1.

disease was more common in those with asbestosis (table 2).

\section{LUNG FUNCTION}

Patients with asbestosis had significantly higher mean levels of TLC \% predicted, TLCO, and KCO than those with cryptogenic fibrosing alveolitis; values for $\mathrm{FEV}_{1}$, FEV $_{1} /$ FVC, and VC were similar (table 1 and fig 1). With exercise the two groups achieved similar degrees of maximum predicted $\mathrm{W}, \dot{\mathrm{V}} \mathrm{E}$, and $\dot{\mathrm{V}}_{2}$, but patients with asbestosis showed less oxygen disaturation.

A significant linear relationship was found for both groups of patients between $\Delta \mathrm{SaO}_{2} / \Delta \mathrm{VO}_{2}$ and both TLCo and TLC (fig 2), showing that subjects with lower levels of TLCO or TLC had greater oxygen
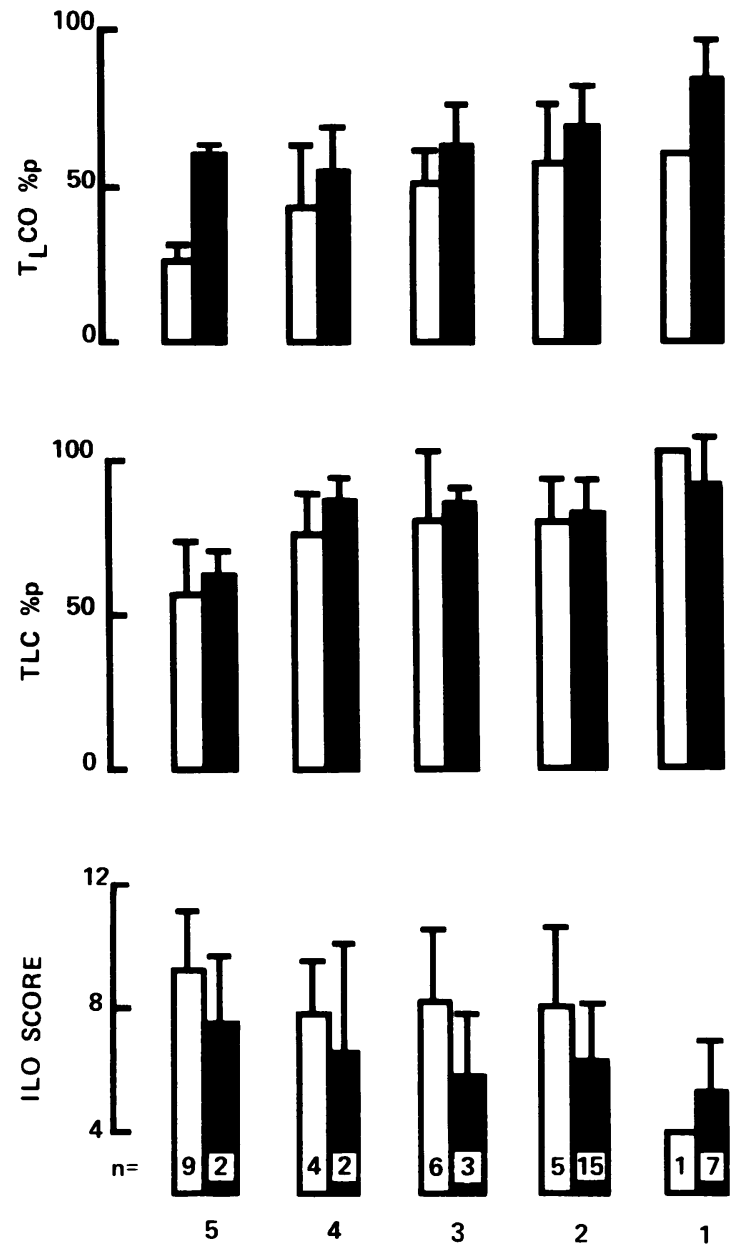

$\triangle \mathrm{SaO}_{2} / \triangle \dot{\mathrm{VO}}_{2} \quad$ CATEGORY

Fig 3 Relation between arterial oxygen desaturation with exercise, stratified for $\triangle S_{a_{2}} / \triangle \dot{V O}_{2}$ and $T L C O, T L C$, and ILO score in patients with asbestosis ( $\square$ ) and fibrosing alveolitis ( $\square$ ). Group $1-$ no fall in $\mathrm{SaO}_{2}$; group $5->10 \%$ fall in $\mathrm{SaO}_{2}$. See "Methods" for definition of $\triangle \mathrm{SaO}_{2} / \triangle \dot{V}_{\mathrm{O}_{2}}$ categories. Abbreviations as in figure 1.

desaturation with exercise. Radiographic profusion tended to be greater in subjects with more severe oxygen desaturation, though there was no significant linear correlation between oxygen desaturation and profusion for either disorder (fig 2).

When the two disorders were compared by stratifying the groups according to $\Delta \mathrm{SaO}_{2} / \Delta \dot{\mathrm{V}}_{2}$ (see "Methods" and fig 3), no significant differences were found except in TLCo for group 5 (that is, more than $10 \%$ fall in oxygen saturation. $\left.\mathrm{l}^{-1} \cdot \mathrm{min}^{-1} ; \mathrm{p}<0.001\right)$. 

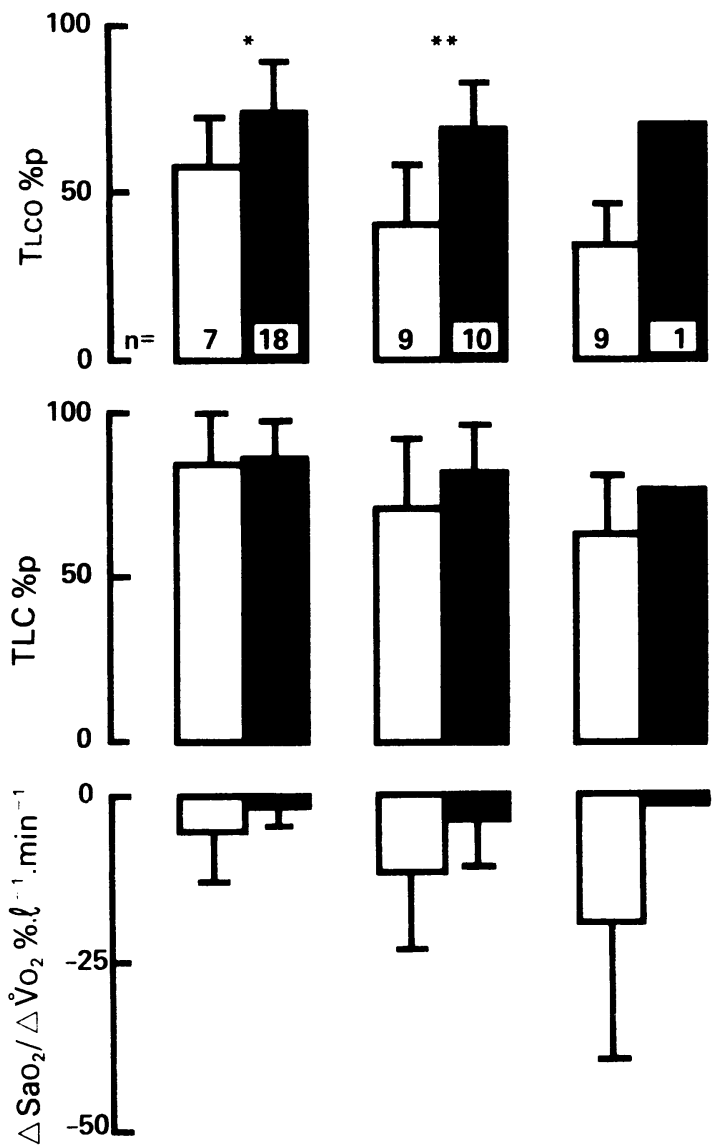

1

2

ILO PROFUSION GRADE

Fig 4 Relation between ILO profusion grade and TLCO, $T L C$, and $\triangle \mathrm{SaO}_{2} / \triangle \dot{\mathrm{V}} \mathrm{O}_{2}$ in cryptogenic fibrosing alveolitis ( $\square$ ) and asbestosis ( $\square$ ). ${ }^{*} p<0.05 ;{ }^{* *} p<0.01$. Abbreviations as in figure 1.

When the two disorders were compared according to the ILO profusion grade (fig 4), TLCO was significantly higher in patients with asbestosis than in those with cryptogenic fibrosing alveolitis, TLC did not differ, and $\Delta \mathrm{SaO}_{2} / \Delta \dot{\mathrm{V}}_{2}$ was lower (that is, less negative), though this did not reach significance ( $p=$ 0.2 for ILO grade $1, p<0 \cdot 1$ for ILO grade 2 ). When ILO profusion grade 1 was compared with ILO grade 2 within each group (fig 4), no significant difference was found for asbestosis or cryptogenic fibrosing alveolitis. For cryptogenic fibrosing alveolitis there were no significant differences between ILO grades 2 and 3 , though there were between grades 1 and 3 for TLCO $(\mathrm{p}<0.005)$ and TLC $(\mathrm{p}<0.025)$; for $\Delta \mathrm{SaO}_{2} /$ $\Delta \mathrm{VO}_{2}$ the difference did not reach significance $(\mathrm{p}$ $<0 \cdot 1)$.

\section{Discussion}

This study shows that for a given degree of arteria oxygen desaturation with exercise patients with asbes- $-\frac{\pi}{\sigma}$ tosis and cryptogenic fibrosing alveolitis have similaro TLco values, total lung capacity, and radiographicis profusion scores. Only in the groups with the greatest arterial oxygen desaturation, where the small number. of subjects and the differences in the degree of exercise $\vec{\omega}$

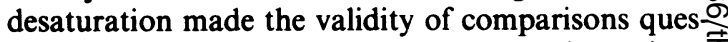
tionable, was TLCo significantly greater in patients with asbestosis than in those with cryptogenic fibros $\frac{\vec{\omega}}{\omega}$ ing alveolitis.

Previous work has shown that radiographici profusion scores are greater in patients with asbestosis ${ }^{\circ}$ than cryptogenic fibrosing alveolitis ${ }^{3}$ for a given reduction in TLCO. This relation was again seen in the present study, which is not surprising as most of the subjects in this study were in the previous one. The pattern of lung function impairment found in this study is similar to that seen in previous studies of patients with interstitial diseases. ${ }^{1314}$ Measures of gas exchange (TLCO and $\Delta \mathrm{SaO}_{2} / \Delta \mathrm{VO}_{2}$ ) were more abnor $ळ$ mal than lung volumes (TLC and VC), and airways ${ }^{\circ}$ function $\left(\mathrm{FEV}_{1} / \mathrm{FVC}\right)$ was near normal. Kco tendeg to be normal in asbestosis and low in cryptogenice fibrosing alveolitis, in keeping with the effects oह pleural disease in asbestosis. ${ }^{15}$

The results of the present study are in agreemen with the findings of Risk and coworkers, ${ }^{16}$ who showed that the desaturation with exercise (measured as alveolar-arterial oxygen tension $\left(\mathrm{Po}_{2}\right)$ gradient) waso less in patients with asbestosis than in those witlp cryptogenic fibrosing alveolitis (divided into usua interstitial pneumonitis and desquamative interstitiab pneumonitis), but that when the patients were्x stratified according to TLCo no significant difference in: the degree of desaturation was present. When the data in the present study were analysed in the same way, no significant difference was found between asbestosis and cryptogenic fibrosing alveolitis

In subjects with diffuse interstitial pulmonary fibrosis the progressive reduction in $\mathrm{SaO}_{2}$ with exercise has been attributed to increased ventilation-perfusion mismatching related to the fibrosing process. ${ }^{17}$ Othe? mechanisms include limitation of oxygen diffusion across the thickened alveolar wall ${ }^{1718}$ and reduction of mixed venous oxygen saturation. ${ }^{18}$ Arterial oxygeno desaturation with exercise, particularly when assessed in relation to oxygen uptake, has been shown to be closely correlated with the morphological severity o? cryptogenic fibrosing alveolitis (that is, the intensity ofo interstitial fibrosis or inflammation). ${ }^{5}$ Desaturation with exercise has been described in patients with a widळ range of interstitial lung disease including asbestosis silicosis, and sarcoidosis, and shown to be correlate 
with morphological severity, ${ }^{19-21}$ but such a correlation has not been reported for asbestosis alone.

The correlation between pathological, radiographic, and physiological features in patients with interstitial lung diseases of varying aetiologies, including asbestosis and cryptogenic fibrosing alveolitis, has been studied by Gaensler and Carrington and their coworkers. ${ }^{19-23}$ Morphological severity (graded for the intensity and extent of both fibrosis and cellularity) was correlated with radiographic profusion of linear or irregular shadows, as seen in asbestosis and cryptogenic fibrosing alveolitis, ${ }^{192122}$ but not with small rounded shadows, as seen in silicosis and berylliosis. ${ }^{1923}$ TLCO was correlated with morphological severity ${ }^{1922}$ and radiographic profusion in asbestosis. ${ }^{22}$ TLCO was not correlated with morphological severity in cryptogenic fibrosing alveolitis ${ }^{19}$ and correlation with radiographic profusion was not reported in cryptogenic fibrosing alveolitis alone. A direct comparison of the structure and function relationships in asbestosis and cryptogenic fibrosing alveolitis was not made in these studies, nor was a comparison made of lung function in these disorders for different grades of morphological severity.

One limitation of the present study was the small number of patients with asbestosis with substantial arterial desaturation with exercise: only one had a TLco below $50 \%$ predicted, compared with 16 patients with cryptogenic fibrosing alveolitis. We cannot therefore provide a valid comparison of subjects with severe asbestosis and cryptogenic fibrosing alveolitis, though we think it likely that a comparison would yield findings similar to those seen in patients with less impaired lung function.

The results of this study suggest that, to the extent that arterial oxygen desaturation with exercise reflects the morphological severity of diffuse interstitial lung disease, asbestosis and cryptogenic fibrosing alveolitis are functionally and radiographically similar. This interpretation is brought into question by the correlation between morphological severity and TLCO in patients with asbestosis but not cryptogenic fibrosing alveolitis found by Gaensler et al. ${ }^{19}$ A direct comparison of the structure and function relationships in asbestosis and cryptogenic fibrosing alveolitis was not, however, made in these studies. Our observation that TLCo is significantly lower in patients with cryptogenic fibrosing alveolitis than in those with asbestosis for radiographic profusion grades 1 and 2 is not readily reconciled with the other results of this study. One possible explanation for the apparent discrepancy is that the chest radiograph is a relatively insensitive index of morphological severity. This is supported by the absence of a significant difference in TLCO, TLC, and $\Delta \mathrm{SaO}_{2} / \Delta \mathrm{VO}_{2}$ between ILO profusion grades 1 and 2 and between grades 2 and 3 for patients with either disorder. An alternative explanation is that the differing relation between TLCO and profusion may reflect a different distribution of interstitial fibrosis or inflammation in the two disorders. For example, predominantly peribronchial lesions in asbestosis may result in less impairment of gas exchange for a given degree of radiographic change. Morphological comparisons with radiographic changes in asbestosis and cryptogenic fibrosing alveolitis would, however, be required to confirm this. A further explanation may be an increased radiodensity of the interstitial changes associated with asbestos fibres, as seen in conditions in which inert radio-opaque dusts have been inhaled.

We are grateful to Dr John J Glancy and Dr Gerard Ryan for grading the chest radiographs according to the ILO classification, Mr Nicholas H de Klerk for advice on the statistical analysis of the data, Ms Dixie Stanford for help in obtaining the radiographs, Ms Joyce James for the artwork, and Ms Elizabeth Bingle for typing the manuscript.

\section{References}

1 Turner-Warwick M. Occupational lung diseases. The scope of the problem. In: Weill H, Turner-Warwick M, eds. Occupational lung diseases. Research approaches and methods. New York: Dekker, 1981:1-10.

2 Parkes WR. Occupational lung disorders. London: Butterworth, 1974:270-357.

3 Cookson WOCM, Musk AW, Glancy JJ. Asbestosis and cryptogenic fibrosing alveolitis: a radiological and functional comparison. Aust NZ J Med 1984;14: 626-30.

4 International Labour Office. Guidelines for the use of ILO international classification of radiographs of pneumoconioses. Geneva: International Labour Office, 1980. (Occupational Safety and Health Series, No 22, revised.)

5 Fulmer JD, Roberts WC, von Gal ER, Crystal RG. Morphologic-physiologic correlates of the severity of fibrosis and degree of cellularity in idiopathic pulmonary fibrosis. J Clin Invest 1979;63:665-76.

6 Turner-Warwick M, Haslam P. Antibodies in some chronic fibrosing lung diseases. I. Non organ-specific autoantibodies. Clin Allergy 1971;1:83-95.

7 Turner-Warwick M, Burrows B, Johnson A. Cryptogenic fibrosing alveolitis: clinical features and their influence on survival. Thorax 1980;35:171-80.

8 DuBois AB, Botelho SY, Bedell GN, Marshall R, Comroe JH Jr. A rapid plethysmographic method for measuring thoracic gas volume: a comparison with a nitrogen washout method for measuring functional residual capacity in normal subjects. $J$ Clin Invest 1956;35:322-6.

9 Ogilvie CM, Forster RE, Blakemore WS, Morton JW. A standardized breath holding technique for the clinical measurement of the diffusing capacity of the lung for carbon monoxide. J Clin Invest 1957;36:1-17. 
10 Cotes JE. Lung function: assessment and application in medicine. 3rd ed. Oxford: Blackwell, 1978:369-70.

11 Miller A, Thornton JC, Warshaw R, Anderson H, Teirstein AS, Selikoff IJ. Single breath diffusing capacity in a representative sample of the population of Michigan, a large industrial state. Predicted values, lower limits of normal, and frequencies of abnormality by smoking history. Am Rev Respir Dis 1983;127: 270-7.

12 Jones NL, Campbell EJM, Edwards RHT, Robertson DG. Clinical exercise testing. Philadelphia: Saunders, 1975.

13 Regan GM, Tagg B, Walford J, Thomson ML. The relative importance of clinical, radiological and pulmonary function variables in evaluating asbestosis and chronic obstructive airway disease in asbestos workers. Clin Sci 1971;41:569-82.

14 Keogh BA, Crystal RG. Clinical significance of pulmonary function tests. Pulmonary function testing in interstitial pulmonary disease-what does it tell us? Chest 1980;78:856-65.

15 Cookson WOC, Musk AW, Glancy JJ. Pleural thickening and gas transfer in asbestosis. Thorax 1983;38: 657-61.

16 Risk C, Epler GR, Gaensler EA. Exercise alveolararterial oxygen pressure difference in interstitial lung disease. Chest 1984;85:69-74.
17 Kelley MA, Daniele RP. Exercise testing in interstitia lung disease. In: Loke J, ed. Symposium on exercise:physiology and clinical applications. Clinics in Ches $\bar{E}$ Medicine 1984;5:145-56.

18 Wagner PD. Multiple inert gas techniques: results in normal subjects and patients. Prog Respir Reß 1981;16:245-9.

19 Gaensler EA, Carrington CB, Coutu RE, Fitzgerald MX Radiographic-physiologic-pathologic correlations in interstitial pneumonias. Prog Respir Res 1975;8: 223-41.

20 Carrington CB, Gaensler EA. Clinical-pathologie approach to diffuse infiltrative lung disease. In $\times$ Thurlbeck WM, Abell MR, eds. The lung. Structure function and disease. Baltimore: Williams and Wilkinş̧ 1978;58-87.

21 Gaensler EA, Carrington CB. Open biopsy for chronię diffuse infiltrative lung disease: clinical, roentgeno은 graphic, and physiological correlations in 502 patients. Ann Thorac Surg 1980;30:411-26.

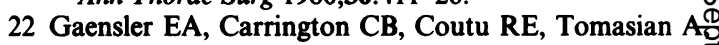
Hoffman L, Smith AA. Pathological, physiological and radiological correlations in the pneumoconioses. Ann NY Acad Sci 1972;200:574-607.

23 Carrington CB, Gaensler EA, Mikus JP, Schachter AW Burke GW, Goff AM. Structure and function iroo sarcoidosis. Ann NY Acad Sci 1976;278:265-83. 